\title{
Mulheres chefes de famílias e as políticas públicas: um ensaio epistemológico
}

\author{
Tânia Ferreira dos Santos Bomfim \\ Urânia Auxiliadora Santos Maia de Oliveira² \\ Felipe Rodrigues Bomfim ${ }^{3}$
}

\begin{abstract}
Resumo: As discussões e análises apresentadas neste esboço de artigo trazem à tona questões referentes aos horizontes epistemológicos dos impactos das políticas públicas, na geração de renda e na transformação da realidade socioeconômica de mulheres, chefes de famílias, no município de Feira de Santana, Bahia, por meio das dimensões de longevidade, educação e renda. Esse tema vem ganhando visibilidade nos espaços de discussão socioeconômica e provocando reflexões sobre as políticas públicas voltadas para o setor, como as dimensões de longevidade, educação e renda no contexto das mulheres chefes de famílias, seus limites e potencialidades. Foi um trabalho de investigação proposto com base na prática de ensino do componente Epistemologia e Construção do Conhecimento, no Programa de Pós-graduação em Gestão e Difusão do Conhecimento, da Universidade Federal da Bahia (UFBA). O objetivo principal é investigar a interlocução teórico/prática de mulheres chefes de famílias, seus desafios, contribuições e potencialidades, relacionando-os com as tensões existentes entre mulheres chefes de famílias, políticas públicas e contextualização teórico-epistemológica. É um estudo desenvolvido com sustentação teóricometodológica na abordagem qualitativa, de natureza aplicada e, do ponto de vista de seus objetivos, visamos uma pesquisa descritiva. Isso posto, surge a questão norteadora da pesquisa: As políticas públicas impactam na geração de renda e na transformação da realidade socioeconômica das mulheres, chefes de famílias, no município de Feira de Santana, Bahia? A base epistemológica do artigo, desdobramento de uma tese em construção, será produzida à luz de estudiosos da temática em questão, entre outros: Platão (2009); Aristóteles (2007); Weber (2003); Haberman (1989); Marshall (1967); Messeder (2012); Peters (1986); Lynn (1980).
\end{abstract}

Palavras-chave: Cidadania. Mulheres. Políticas públicas.

Abstract: The discussions and analyzes presented in this draft article raise questions about the epistemological horizons of the impacts of public policies, on income generation and on the transformation of the socioeconomic reality of women, heads of families, in Feira de Santana city, Bahia, Brazil, through longevity, education and income dimensions. This theme has been gaining visibility in the spaces of socioeconomic discussion and provoking reflections on the public policies focused on this sector, as well as the longevity, education and income dimensions in the female heads of families context, their limits and potentialities. It was a research project proposed from the teaching practice of the subject Epistemology and Construction of Knowledge, in the Postgraduate Program in Management and Diffusion of Knowledge, on the Universidade Federal da Bahia (UFBA), with the main objective to investigate the theoretical / practice of women heads of families what the challenges, the contributions and the potentialities of the same, relating them with the tensions existing between women heads of families, public policies and epistemological theoretical contextualization. It is a study developed with theoretical and methodological support in the qualitative approach, of applied nature and from the point of view of its objectives we aim a descriptive research. Therefore, the research question arises: The public policies impact on the generation of income and on the transformation of the socioeconomic reality of women, heads of families, in Feira de Santana city/Bahia/Brasil? The epistemological basis of the article, unfolding of a thesis under construction, will be produced in the light of scholars in the subject matter, as Platão (2009); Aristoteles (2007); Weber (2003); Haberman (1989); Marshall (1967); Messeder (2012); Peters (1986); Lynn (1980) among others.

Keywords: Citizenship. Women. Public policy.

\footnotetext{
${ }^{1}$ Mestre em Contabilidade pela FVC. Doutoranda do Doutorado Multidisciplinar e Multi-institucional em Difusão do Conhecimento (DMMDC) da Universidade Federal da Bahia (UFBA). Professora da Universidade do Estado da Bahia. E-mail: tbomfim@,uneb.br.

${ }^{2}$ Doutora em Educação pela Universidade Federal da Bahia (UFBA). Professora da UFBA. E-mail: uraniamaia@gmail.com.

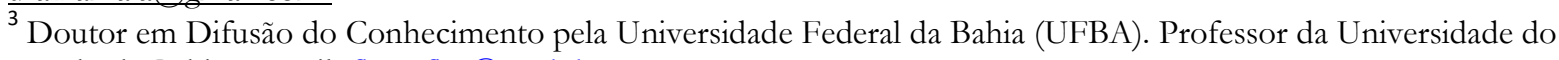
Estado da Bahia. E-mail: fbomfim@uneb.br.
} 


\section{Introdução}

As discussões e análises apresentadas neste texto trazem à tona questões referentes às mulheres chefes de famílias em Feira de Santana, Bahia, tema que vem ganhando visibilidade nos espaços de discussão educacional e provocando reflexões sobre a difusão e gestão das políticas públicas entre essas famílias e as implicações de tais ações na Bahia. É um projeto de investigação que tem como objetivo principal avaliar o impacto das políticas públicas, na geração de renda e na transformação da realidade socioeconômica dessas mulheres, por meio do IDHM-RENDA, correlacionando com as tensões existentes entre essa formação familiar e as políticas públicas.

O fio condutor por meio do qual tornou possível e motivou o interesse por esse objeto de pesquisa relaciona-se com a função de Delegada do Conselho Regional de Contabilidade, exercida por uma das autoras, a qual se deparou com os dados relativos ao objeto de pesquisa; criação e participação da Frente Negra Feirense (FRENEFE), momento em que vivenciou a realidade das "mulheres chefes de famílias", seus limites e potencialidades na cidade de Feira de Santana, Bahia, e a ausência de políticas públicas para essas mulheres.

Dessa maneira, estudos dessa natureza servem de instrumento de negociação e diálogo com as instituições promotoras do desenvolvimento territorial, visto que: contribuem para a integração das políticas públicas no território; fomentam o debate sobre a sustentabilidade, colaborando para a identificação de novos eixos aglutinadores; concorrem para o controle social das políticas públicas e empoderamento da sociedade civil.

Este estudo será desenvolvido com sustentação teórico-metodológica na abordagem qualitativa, tendo como dispositivos de coleta de dados: a entrevista, o levantamento bibliográfico e a aplicação de questionário nas instituições onde essas mulheres laboram. A questão que norteia a pesquisa é: As políticas públicas impactam na geração de renda e na transformação da realidade socioeconômica das mulheres, chefes de famílias, no município de Feira de Santana, Bahia?

O referencial teórico será produzido à luz de estudiosos na temática em questão, como: Santos (2000); Carvalho (1998); Almeida (2005); Guimarães (2001); Messeder (2008); Nogueira (2010); Almeida (2005); Moser (2005); IPEA (2010); IBGE (2010), entre outros. Espera-se que a pesquisa apresente aspectos latentes da realidade da família contemporânea por meio das mulheres chefes de famílias, em uma tentativa de compreensão dos desafios que lhes são postos.

$\mathrm{O}$ texto está dividido em quatro partes. $\mathrm{Na}$ primeira, realizamos um percurso histórico, dialogando com autores diversos, como os filósofos Platão, Aristóteles e Haberman, com vistas a correlacioná-los com a contemporaneidade. Na segunda parte, investigamos quais são as origens das políticas públicas e elegemos como base epistemológica: Weber e Marshall. Na terceira parte, apresentamos a análise, ainda que parcial, da condição de mulheres chefes de famílias em Feira de Santana, 
Bahia, partindo do entendimento de que as políticas públicas são um conjunto de ações e decisões do governo, voltadas para a solução (ou não) de problemas da sociedade. A última parte pontua algumas considerações a respeito do objeto de estudo proposto, considerando que os achados podem e devem ser complementados na busca de um diálogo permanente, que possibilite maior clareza às formulações de políticas públicas voltadas para as "mulheres chefes de famílias" definição da economia criativa.

\section{Horizonte epistemológico da mulher...procurando Habermas}

Preliminarmente, sabe-se que os temas da mulher e do feminino são pouco lavrados na tradição filosófica. Destarte, com vistas a determinar um horizonte epistemológico da mulher, mesmo renunciando a vias de repercussão da discriminação feminina pelo homem e seu ar de superioridade atemporal que também recai no vasto epistemológico e intelectual, é necessário um esforço analítico às reflexões filosóficas em face do filosofema MULHER, de acordo com a totalidade dos sistemas daqueles que sobre o mesmo se dedicaram a escrever, mesmo que sob um horizonte secundário, ou que, ao falar sobre temáticas "aceites" (outras) também repercutiram o universo feminino.

Nesse diapasão, é inegável que Platão e Aristóteles foram vanguardistas, traçando orientações que deixam vestígios até hoje. Historicamente, Platão se apresenta ao lado dos adeptos à igualdade, enquanto Aristóteles se vincula aos que sustentam uma latente diferença entre homem e mulher - estando ambos inseridos em uma sociedade sexista.

Em sua mais célebre obra, A República, especificamente no livro V, Platão apresenta uma autêntica e promissora proposta, analisar um ideal societário, cuja possibilidade de participação da mulher no funcionamento da pólis ateniense era viável, dando-lhe uma perspectiva ativista na dinâmica da sociedade.

No livro V, ao versar sobre o papel da mulher na sociedade, por meio da figura de Sócrates, o filósofo assevera:

\footnotetext{
- Portanto - prossegui eu - se se evidenciar que, ou o sexo masculino, ou o feminino, é superior um ao outro no exercício de uma arte ou de qualquer outra ocupação, diremos que se deverá confiar essa função a um deles. Se, porém, se vir que a diferença consiste apenas no facto de a mulher dar à luz e o homem procriar, nem por isso diremos que está mais bem demonstrado que a mulher difere do homem em relação ao que dizemos, mas continuaremos a pensar que os nossos guardiões e as suas mulheres devem desempenhar as mesmas funções. (A República (R), V. 454d-e)
}

Esse modelo social, em que a mulher ateniense encontra uma função relevante na máquina pública, vivendo em pé de igualdade com o homem, era completamente destoante do pensamento 
dominante que vigorava a época, sobretudo, quando se sabe que a atuação feminina acompanhava contornos bem nítidos, cuja demarcação lhe permitia apenas o domínio do privado - negando-lhe, inclusive, a cidadania.

Entretanto, não se engane. É evidente que por mais que se destaque a possibilidade de certas mulheres ascenderem como guardiãs da cidade, desde que devidamente instruídas, ainda restavam traços de ideologias sobre a supremacia masculina em face da inferioridade e desprezo do feminino. Prova disso são certas passagens extraídas de sua obra, A República, como exemplifica o prosseguimento do diálogo supracitado em que Sócrates pergunta (455c-d): "Sabes, de entre as ocupações humanas, alguma em que o sexo masculino não sobreleve o feminino? Ou vamos perder tempo a falar da tecelagem ou da arte da doçaria e da culinária, nas quais parece que o sexo feminino deve marcar, e quando é derrotado, não há nada de mais risível?”

O interlocutor responde (455d): "Dizes a verdade, ao afirmar que em tudo, por assim dizer, um sexo sobreleva em muito o outro. Contudo, há muitas mulheres que são melhores que os homens para numerosas tarefas. No entanto, de um modo geral, é como tu dizes".

Sócrates, então, conclui (455d-e):

“(...) não há na administração da cidade, nenhuma ocupação, meu amigo, própria da mulher enquanto mulher, nem do homem, enquanto homem, mas as qualidades naturais estão distribuídas de modo semelhante em ambos os seres, e a mulher participa de todas as atividades, de acordo com a natureza, e o homem também, conquanto em todas elas a mulher seja mais débil do que o homem." (Platão, República, livro V, 455 d $-\mathrm{e})$.

Destarte, na aparente impossibilidade de neutralidade do binômio masculino-feminino nesse horizonte epistemológico constituído pelos filósofos gregos, criou-se uma hierarquia, melhor dizendo, uma sobreposição do gênero masculino em face do feminino, condição em que este foi inferiorizado ou discriminado, tanto no seio social como na cultura filosófica.

Nesse sentido, Aristóteles apud Reale (2007), ora aluno de Platão, mediante o conceito de política e análise da organização estatal como uma estrutura composta por uma comunidade de famílias, as quais resultam da junção de vários indivíduos, observava que a família - cuja existência, logicamente, antecedia o estado e este constituindo um reflexo daquela - representava o fundamento da sociedade, estruturandose em quatro elementos: o chefe da família, a mulher, os bens, e os escravos.

Para fundamentar a condição da mulher no cenário da polis, Aristóteles toma como motor principal as diferenças existentes no corpo, já que aquela é um ser humano imperfeito, chegando a afirmar que “a fêmea é um macho mutilado" (Geração dos Animais, 737a 24-25). Por conseguinte, como leciona 
Ferreira (1998), em O que os filósofos pensam sobre as mulberes, "Aristóteles fundamenta a diferença destas no corpo. A alma é a forma do corpo. O corpo das mulheres é mais fraco, consequentemente a alma também o é. O critério passa por justificações biológicas como são a do calor, do frio ou da espessura dos fluidos".

Nesse cenário esboçado por Aristóteles, conforme Reale (2007), conquanto tenha seu acesso à cidadania restrito, em meio ao descontrole de suas emoções, distanciando-se da razão, a incapacidade intelectual de atingir papéis chaves na política da pólis, seu campo de atuação, as teses aristotélicas, ainda assim apresentam aspectos de valorização da mulher. Elas têm uma atuação de destaque na família, na economia doméstica, nos assuntos do lar - ainda que subordinadas, em outros aspectos, às decisões do homem, a quem competia guiar os filhos e as mulheres. A sua especificidade, então, define-se na seara do privado e isso era determinante para a harmonia social.

Ante o exposto, o que se percebe na Antiguidade Clássica é a restrição de atuação da mulher ao domínio privado, melhor dizendo, ao lar. Ora, de fato, é nesse reconhecimento do papel desempenhado no interior da família e, consequentemente, como fator principal para a preservação da família e bem-estar no domínio privado, é que se constituiu a figura da mulher como dona de casa.

Atualmente, superadas as ideias de banalização da escravidão, bem como a inferioridade/imperfeição da mulher, passou a existir um cenário propenso ao incremento de número de lares com a chefia da figura feminina, em meio à injeção da mão de obra feminina no mercado de trabalho. Esse movimento não é um fenômeno isolado, mas resultante de uma série de exclamações que se perpetuaram no tempo.

Como bem leciona Thomas Humprey Marshall, ao analisar o desenvolvimento da cidadania e a concretização dos direitos fundamentais na Inglaterra, ao longo dos séculos XVIII, XIX e XX, com “a intenção de identificar as conexões de natureza social que permitem relacionar cada elemento da cidadania em uma dimensão sincronizada" (LEANDRO, 2006, p. 2 apud MASTRODI e AVELAR, 2017, p. 2), a plena e efetiva cidadania decorre da coexistência de múltiplos direitos que se reúnem em três grandes grupos: direitos cíveis, que abrangem a liberdade em sentido amplo (liberdade de ir e vir, liberdade de imprensa, liberdade de culto, entre outros); direitos políticos, que se traduzem no direito ao voto e ao de ser votado; e direitos sociais, que se referem ao direito ao trabalho, educação, saúde, segurança social etc. Destarte, Marshall (2002) defendia que os homens livres, em teoria, eram capazes de gozar dos direitos, a cidadania se desenvolve pelo enriquecimento do conjunto de direitos de que eram capazes de gozar.

Aplicando a pirâmide de Marshall em uma análise um tanto quanto pretensiosa à experiência feminina, em face da conquista dos seus direitos, em uma correlação entre cidadania e democracia, hoje é possível avistar uma transformação da realidade socioeconômica das mulheres. Elas figuram cada vez mais como chefes de famílias e geradoras de rendas, porque houve um processo paulatino de conquistas, assim como o desenvolvimento da cidadania na Inglaterra. Primeiro, o triunfo de seus direitos civis, que lhes concederam a liberdade de ir e vir e ocupar outros espaços além do lar; em segundo plano, com a 
cristalização e pleno exercício desse primeiro grupo de direitos, houve a concepção de direitos políticos. Em momento ulterior, mediante a consolidação dos direitos civis e político, passaram a ter acesso aos direitos sociais - em especial, o trabalho - em condições dignas (estado social de direito, ou seja, bemestar social).

Dentro desse paradigma cidadania $\mathrm{x}$ democracia, fator crucial para o desenvolvimento socioeconômico das mulheres e implantação de políticas públicas, é fundamental uma reflexão sobre a importância do agir comunicativo, sobretudo, da mulher, no universo democrático, invocando, para tanto, as lições do consagrado filósofo Jürgen Habermas, que se dedicou a pensar os principais problemas sociais e humanos com base na matriz da comunicação.

Assim, "a teoria do agir comunicativo surge como uma teoria voltada para a compreensão da dimensão da verdade não enquanto conformidade da mente com as coisas, mas como fruto de uma experiência intersubjetiva e dialógica no espaço social" (BITTAR, 2015, p. 552). O que isso quer dizer? Ora, a interpretação que se faz é, em face de um filosofema, o agir comunicativo opera para determinada coletividade buscar, por meio do diálogo e da troca de informações (intersubjetividade), o consenso - que, em síntese, se traduz em "uma ideia comunitária a ser desenvolvida pelo grupo que pensa seus problemas em comum, e, portanto, constrói, comunicativamente, suas soluções (morais e jurídicas)" (BITTAR, 2015, p. 552) - esse consenso então passa a ser tomado como pressuposto de imparcialidade na formação do juízo de verdade e fim colimado da realização discursiva.

Nesse diapasão, surge a pergunta: o que a ética discursiva habermasiana teria a acrescentar no horizonte epistemológico da mulher, em especial, no que tange às afirmações que Platão e Aristóteles propuseram fazer? Propedeuticamente, dediquemos um esforço analítico ao que o filósofo explana:

\footnotetext{
"A ética do Discurso não dá nenhuma orientação conteudística, mas sim, um procedimento rico de pressupostos, que deve garantir a imparcialidade da formação do juízo. O Discurso prático é um processo, não para a produção de normas justificadas, mas para o exame da validade de normas consideradas hipoteticamente. É só com esse proceduralismo que a ética do Discurso se distingue de outras éticas cognitivistas, universalistas e formalistas, tais como a teoria da justiça de Rawls" (HABERMAS, 1989, p. 148).
}

Ora, a "particular preocupação dessa ética discursiva são as condições de validade pelas quais se produzem os diversos discursos (jurídicos, políticos, morais, educacionais...)" (BITTAR, 2015, p. 553). Por conseguinte, como se pode concluir um raciocínio válido sobre o gênero feminino se todos os envolvidos nesse filosofema não são convidados ao debate? Não há legitimidade nisso. A mulher não era considerada cidadã na pólis ateniense, de modo que não tinha direito à fala no cenário político-intelectual. Era esperado dela o silêncio e, consequentemente, a supressão do seu ativismo. Sendo que, sob a ótica da 
razão comunicativa, a falta de proceduralismo, o convite à participação e a ausência de consenso representam invalidade do discurso, representando um contraponto às ideias platônicas e aristotélicas. Vejamos:

\begin{abstract}
“A intersubjetividade de um grau mais alto (die höherstufige Intersubjektivität), que comunga a perspectiva de cada um com a perspectiva de todos, pode constituir-se apenas sob os pressupostos comunicativos de um discurso ampliado universalmente, no qual todos os possivelmente envolvidos possam participar e tomar posição com argumentos numa postura hipotética em vista das pretensões à validade (tornadas problemáticas a cada momento) de normas e modos de ação.” (HABERMAS, 1989, p. $15)$.
\end{abstract}

Ante o exposto, "significa que pensar e agir em comum se somam, no processo da produção de sentido que se dá em comum entre falantes, abandonando-se a ideia de que as verdades são formadas por um sujeito (ou alguns sujeitos) que buscaria em normas abstratas e unilateralmente deduzidas verdades contidas em uma razão solitária, autossuficiente(...)" (BITTAR, 2015, p. 555). Por isso, à luz da ética discursiva habermasiana, é nula de validade a afirmação de que o lugar da mulher é no domínio privado, destituindo-a do domínio público e socioeconômico - sobretudo, quando o discurso parte de uma sociedade sexista que limitou tal discussão a um campo restrito aos homens, como se pode ver nos textos de Platão e Aristóteles. Além do mais, hoje, quando se sabe que há um incremento no número de mulheres chefes de família, capazes de gerar renda e emprego em um universo que, por muito tempo, lhe negou o acesso à intelectualidade e ao mercado de trabalho.

A mulher deixa de ser, segundo o discurso fundado no proceduralismo de Habermas, um eco da linguagem masculina buscando entender sobre sua natureza e função social. Com efeito, nessa nova narrativa de alteridade, a mulher passa a figurar, como é o caso deste estudo, tanto como objeto quanto como investigadora.

\title{
Horizonte epistemológico das políticas públicas... em busca de Weber
}

A contemporaneidade apresenta-nos um cenário bastante complexo, em que a diversidade é uma de suas marcas essenciais. Nesse contexto, as diferenças se apresentam como uma construção histórica que engloba uma multiplicidade de aspectos, que vão desde as questões naturais àquelas que dizem respeito à natureza, à família, à economia, à política e ao poder.

Para que seja possível uma compreensão ampla acerca do que são as políticas públicas e seu papel na promoção do bem-estar da sociedade, é necessário discutir suas bases epistemológicas, características, 
formulação e implementação, tendo em vista sua complexidade na busca de assegurar direitos de cidadania de forma ampla ou restrita para determinado seguimento social, cultural, étnico ou econômico.

Não existe uma única nem melhor definição sobre o que seja política pública. Nessa perspectiva, apresenta Peters (1986, p. 77) "política pública é a soma das atividades dos governos, que agem diretamente ou através de delegação, e que influenciam a vida dos cidadãos"; Lynn (1980) define-a como um conjunto de ações do governo que irão produzir efeitos específicos; Dye (1984) conceitua política pública como o resultado de um processo que envolve diferentes estágios e atores sociais; Weber (2000) destaca que as políticas públicas possuem uma intencionalidade racional, trata-se de atividades orientadas para um fim.

\begin{abstract}
As muitas definições enfatizam o papel da política pública na solução de problemas. Críticos dessas definições, que superestimam aspectos racionais e procedimentais das políticas públicas, argumentam que elas ignoram a essência da política pública, isto é, o embate em torno de ideias e interesses. Por concentrarem o foco no papel dos governos, essas definições deixam de lado o seu aspecto conflituoso e os limites que cercam as decisões dos governos. Deixam também de fora possibilidades de cooperação que podem ocorrer entre os governos e outras instituições e grupos sociais. [...] Pode-se, então, resumir política pública como o campo do conhecimento que busca, ao mesmo tempo, colocar o "governo em ação" e/ou analisar essa ação (variável independente) e, quando necessário, propor mudanças no rumo ou curso dessas ações (variável dependente). A formulação de políticas públicas constitui o estágio em que os governos democráticos traduzem seus propósitos e plataformas eleitorais em programas e ações, que produzirão resultados ou mudanças no mundo real. (SOUZA, 2007, p. 68-9).
\end{abstract}

As políticas públicas abrangem um conjunto de ações nos setores econômico, social, cultural, ambiental, entre outros, e os instrumentos e normas que as instituem e estruturam a ação do Estado são fundamentadas pelo direito coletivo. A qualidade do espaço da esfera pública é fundamental para que se possa criar um ambiente democrático favorável para a formação e execução de políticas públicas. Conforme abordagem adotada neste texto, a concepção de esfera pública remete ao caráter das relações entre Estado e Cidadania, envolvidos em dinâmicas de interesses coletivos e dimensões sociais e políticas.

Max Weber (1864-1920), na obra “A Política como Vocação”, discute a lógica interna, própria da política enquanto campo de ação do homem político e fonte da racionalidade de cidadãos ou súditos. $\mathrm{O}$ autor leva-nos a entendê-la como "a direção do agrupamento político hoje denominado Estado ou a influência que se exerce em tal sentido". Vale ressaltar que o Estado é uma estrutura e é formado por pessoas, que as políticas públicas dependem de vontade política, a qual decorre também da ação de pessoas. Portanto a concepção de política é indissociável do Estado, entendido por Weber como "relação de dominação do homem sobre o homem".

De outra forma, como "o conjunto de esforços feitos com vistas a participar do poder ou a influenciar na divisão do poder, seja entre Estados, seja no interior de um único Estado”.

Ainda relacionando as políticas públicas, Weber (2000) considera a burocracia um grupo organizado dotado de funções técnicas específicas, uma expressão da própria sociedade em que se insere e, simultaneamente, está inserido no Estado como parte da administração, elaboração e execução das atividades públicas. Essa reflexão nos permite perceber a burocracia na condição de sujeito das políticas 
públicas. Conforme Weber (2000), a burocracia deve ser o sujeito portador de uma racionalidade e de uma ação que, dada a sua especificidade, respalda tecnicamente as ações do Estado. Certamente, Weber não chegou a discutir a burocracia como sujeito do processo das políticas públicas. Ao entendê-la como ação do Estado, na sociedade, podemos inferir a burocracia como fundamento racional no processo que culmina com a intervenção estatal, nas demandas sociais.

Corroborando com Weber, Marshall (1967, p. 6) discorre de forma específica sobre as políticas sociais que compreendem políticas de governos "relativas à ação que tem um impacto direto no bem-estar dos cidadãos ao dotá-los de serviços ou renda".

Marshall analisou o desenvolvimento da cidadania como desenvolvimento dos direitos civis, seguidos dos direitos políticos e dos direitos sociais. Introduziu o conceito de direitos sociais, sustentando a tese de que a cidadania é plena se dotada de todos os três tipos de direito, condição que se relaciona à classe social. Nesse sentido, é necessário discutir as políticas públicas para as mulheres conforme a teoria de Marshall sobre cidadania.

Nascimento (2016) ressalta que, embora a ideia de cidadania não tenha sido inventada por Marshall, estando presente em períodos históricos distintos, como na Grécia e Roma antigas, bem como em cidades do Renascimento, sua definição tendeu a prevalecer na segunda metade do século XX.

"A cidadania é um status concedido àqueles que são membros integrais de uma comunidade" (MARSHALL, 2002, p. 24). Assim, em um sistema de medida de igualdade, todos aqueles que possuem o "status" também possuirão um mesmo conjunto de direitos e obrigações. O que nos leva a um tipo de classe social como as camadas de um sistema hierárquico, que "divide uma sociedade numa série de espécies humanas distintas, hereditárias (...) uma instituição em seu próprio direito" (MARSHALL, 2002, p. 25). Contudo, Sylvia Walby (2004) apud Nascimento (2016), aponta a ausência da questão de gênero no conceito de Marshall, e propõe que às dimensões da cidadania destacadas pelo autor (política, civil e social) sejam incluídos direitos específicos das mulheres de modo a contemplar a questão de gênero.

Assim, do ponto de vista teórico-conceitual, a política pública em geral e a política social em particular são campos multidisciplinares, e seu foco está nas explicações sobre a natureza da política pública e seus processos. Por isso, uma teoria geral da política pública implica sintetizar teorias construídas no campo da sociologia, da ciência política e da economia.

\section{Teorias e práticas: um olhar além horizontes}

Desse modo, a "mulher chefe de família", no município de Feira de Santana, é um tema recente nas rodas acadêmicas formais de discussão, mas com o recorte machista e de vulnerabilidade social. Este trabalho trata o assunto sob uma perspectiva da família na contemporaneidade, a qual suplanta o aspecto de gênero.

A nossa problemática se envolve na discussão sobre a contribuição das "mulheres chefes de família na Bahia e suas implicações nas escalas local e regional. As "mulheres chefes de famílias", por 
exemplo, estão presentes em diversos municípios do Estado da Bahia, transformando as realidades locais com o auxílio de seus processos laborais: trabalho, educação de filhos, sustentação e manutenção da família e qualificação. Essas atividades, na Bahia, limitavam-se e ainda se limitam à perspectiva de aumento da renda familiar sem se perceber como principal mantenedora da família. No entanto, já existem iniciativas na direção de mensurar e promover os limites e potencialidades da "mulher chefe de família" na Bahia, a exemplo do Banco da Mulher, que evidencia uma nova realidade política para as mulheres.

Contudo, na atual configuração institucional da "mulher chefe de família", a mensuração e a promoção dessa mulher implicam perceber as diretrizes e iniciativas do governo para seu desenvolvimento. A investigação da família, na contemporaneidade das políticas públicas assistencialistas, e seu alcance concorrem para esse fim.

Nesse sentido, surgiu a inquietação da pesquisa para responder à pergunta: de que maneira as políticas públicas impactam na geração de renda e na transformação da realidade socioeconômica das mulheres, chefes de famílias, no município de Feira de Santana, Bahia?

A dimensão da "mulher chefe de família" assume um papel central, à medida que afeta sobremaneira as forças produtivas, a produção do conhecimento e o novo desenho da família na contemporaneidade. Nesse processo histórico, a distribuição das oportunidades nos contextos familiares, bem como suas subjetividades, em determinado local, define e especifica sua realidade.

A realidade da mulher chefe de família tem sido pauta de discussão em diversos países, de modo especial nos países da América Latina e em alguns pertencentes à União Europeia. Isso se verifica pelas representações institucionais componentes do projeto "Observatório Internacional para os Direitos e as Oportunidades das Mulheres Solteiras e Chefes de Família”, coordenado pela Itália. De acordo com Almeida (2005), a instabilidade das uniões vem contribuindo para o aumento do número de famílias em que a responsabilidade recai sobre as mulheres. Estas, geralmente são divorciadas, viúvas ou solteiras.

Cabe, então, compreender o conceito de chefe de família. Considerando o fato de que as mulheres não constituem um grupo homogêneo e universal, ao contrário, são heterogêneas e situam-se em condições e contextos diversos, a expressão "mulheres chefes de família" deve considerar também uma diversidade de categorias, visto que, além do gênero, abrange outras dimensões, como classe, raça/etnia e idade/geração (MACEDO, 2001).

Existe também o conceito associado à negação da chefia masculina, seja pela ausência do parceiro no domicílio, seja pela condição dessas mulheres, geralmente, viúvas, mães solteiras ou separadas com dependentes (CARVALHO, 1998). O conceito de chefe de família aplica-se, ainda, às mulheres que mesmo contando com a figura masculina em casa, trabalha, sustenta e administra o lar.

Dessa forma, a realidade da mulher chefe de família tem diferenças peculiares, se comparada à da família chefiada por homens. As famílias comandadas por mulheres apresentam um maior grau de 
propensão à pobreza, as disparidades ocorrem principalmente em virtude do gênero e da má remuneração. (ALMEIDA, 2005). Entre as diferenças presentes nas famílias em que a mulher é chefe de família estão:

os mais elevados níveis de desemprego, o menor número de horas trabalhadas em virtude das obrigações domésticas, os salários mais baixos, as maiores dificuldades para ingressar no mercado de trabalho, o acesso mais restringido aos recursos produtivos, além de outros elementos...”(Guimarães (2001, p.164).

Nesse contexto, a mulher vivia sob a guarda do pai e, posteriormente, sob a tutela da família do marido. Com o casamento, passava a render culto aos antepassados do marido. Assim, tanto ela quanto os filhos perdiam qualquer direito à herança do pai, pois o que, preponderantemente, diferenciava aquelas famílias era o compartilhar do mesmo culto doméstico (NOGUEIRA, 2012). De modo a iluminar tais afirmativas, Coulanges (2001, p.103-104) observa:

Cada fratria ou cúria possuía um chefe chamado curião ou fratriarca, cuja função principal era presidir aos sacrifícios [...] A fratria tinha suas assembleias, suas deliberações e podia instituir decretos. Nela, tanto quanto na família, havia um deus, um culto, um sacerdócio, uma justiça, um governo. Era uma pequena sociedade moldada exatamente sobre a família. A associação continuou naturalmente a crescer e segundo mesmo sistema. Várias cúrias ou fratrias se agruparam e formaram uma tribo [...] Da tribo se passava à cidade, mas isso não causava a dissolução das tribos, e cada uma delas continuava a formar um corpo [...] Assim, não é um conjunto de indivíduos. Ela é uma confederação de vários grupos constituídos antes delas e que ela permite que subsistam.

A mulher tinha, então, a função de gerar, no mínimo, um primogênito para o marido, responsável pela perpetuação do culto doméstico, pelo patrimônio e demais tradições familiares. Posteriormente, com a cristianização de Roma, atrela-se a essa concepção cultural a ideia (preconceituosa) de que o gênero feminino, representado por "Eva", foi responsável pela queda da humanidade (NOGUEIRA, 2012). Dessa forma, o trabalho doméstico fora do lar era incompatível com a família e a moralidade cristã até a Revolução Industrial.

Na sociedade denominada industrial, a mulher de classe menos abastarda ia para as fábricas, o que dava início a uma separação entre o trabalho doméstico e o trabalho remunerado, fora do lar. Este era subalterno e, por ser mais barato, muitas vezes, substituía o trabalho masculino. Percebe-se dessa situação uma crise de gênero, em que os homens se queixavam de perder seus postos.

A mulher assumiu, então, uma dupla jornada. Passou, portanto, a exercer atividades fora de casa, como escrava (um retorno à antiguidade), prostituta e outros serviços degradantes. Cabe destacar que, ao desempenhar tais profissões, a mulher era quase impedida de manter laços familiares. 
Com as guerras mundiais, no início do século $\mathrm{XX}$, o ocidente se viu obrigado a fazer uso do trabalho feminino, uma vez que, diante das perdas em virtude das guerras, o número de homens ficava escasso. Essa segunda (ou terceira - se considerar a prostituição como primeira) inserção da mulher no mercado de trabalho ocorre de forma qualificada e definitiva. É, sem dúvida, a que emancipa as mulheres dos pais e dos maridos.

Já na década de 1960, com a revolução sexual, a mulher passa a ser responsável pela decisão de conceber ou não. Nesse período, com a liberação da sexualidade, desvinculada do ato de procriar, fixa-se a ideia de que o sexo tem caráter psicossocial e não meramente psicológico. Já na década de 1970, a mulher insere-se de forma mais acentuada no mercado de trabalho, mas ainda cumprindo dupla jornada, sentindose culpada pela falta de tempo com os filhos e, mesmo que em menor grau, submissa ao marido. Dessa forma, com décadas de luta, a mulher conquistou seu lugar como agente político, econômico e social no mundo contemporâneo.

Como fator determinante disso, no Brasil, o Instituto Brasileiro de Geografia e Estatística (IBGE) não utiliza mais a expressão "chefe de família", antes atribuída ao gênero masculino, e que alcançava aquele que contribuía com uma parcela maior no orçamento da família. Tal fato ocorre devido à mudança do papel da mulher na economia brasileira. A figura feminina passou, muitas vezes, a agir exclusivamente na condição de provedora da entidade familiar. Nas pesquisas mais recentes, o IBGE (2010) trabalha com a locução "pessoa de referência" da família, "a pessoa responsável pela unidade domiciliar (...) ou que assim fosse considerada pelos demais membros do grupo" (ALMEIDA, 2005).

A mulher contemporânea é bastante diferente da mulher da antiguidade, mas ainda guarda "lembranças" exclusivamente suas. A "obrigação" da maternidade, de cuidar dos filhos, a responsabilidade pela boa organização do lar, por exemplo, são aspectos preservados pelo universo feminino.

Não obstante os tantos avanços, a mulher ainda enfrenta muitos obstáculos, principalmente no mercado de trabalho, o qual, segundo argumenta Messeder (2012, p. 103), alicerça-se em dois princípios: “a) o da separação - existem trabalhos de homens e trabalhos de mulheres; b) o hierárquico - trabalho de homem vale mais que trabalho de mulher".

Conforme estudo apresentado pelo Instituto de Pesquisa Econômica Aplicada (IPEA, 2010), por meio do cruzamento de dados da Pesquisa Nacional por Amostra de Domicílio (PNAD, 2009), divulgados pelo IBGE, no período compreendido entre os anos de 2001 a 2009, constatou-se que a proporção de famílias chefiadas por mulheres no Brasil subiu de, aproximadamente, 27\% para 35\% do total. Em 2009, 21.933.180 famílias identificaram uma mulher como a principal responsável pelo lar.

O perfil dessas mulheres é de solteiras, separadas ou viúvas com filhos, solteiras sem filhos, morando sozinhas, entre outras características. A pesquisa aponta ainda, um perfil que chama atenção: mulheres casadas chefiando a familia mesmo com um marido ou companheiro em casa, com ou sem 
filhos. Nesse caso, segundo o IPEA (2010) “o tradicional arranjo casal com filhos com um homem como 'cabeça do casal' passa a ser substituído por situações em que a mulher é tida como a pessoa de referência na casa". Em 2009, 14,2\% dos casais com ou sem filhos eram chefiados por mulheres.

Em 2013, o Governo Federal, por meio da Secretaria de Políticas para as Mulheres, editou o Plano Nacional de Políticas sobre as Mulheres 2013-2015, trazendo uma série de ações voltadas à inserção da mulher em todos os níveis sociais e econômicos. Seria o primeiro resultado concreto da busca de sinergia intergovernamental pela promoção da igualdade de gênero e das políticas para as mulheres, um passo importante.

Observa-se a demanda por políticas públicas que promovam a construção da autonomia econômica das mulheres, especialmente no que diz respeito à questão sobre para quem políticas específicas devem ser formuladas, de modo a garantir-lhes condições paritárias de participação no mercado de trabalho.

Por outro lado, reconhecer a situação das mulheres depende de estruturas que vocalizem e possam concretamente demonstrar a responsabilidade do Estado pela não discriminação.

\section{Reflexões finais}

O breve estudo, ora apresentado, está longe de esgotar a questão das mulheres chefes de famílias, a desigualdade de gênero e políticas públicas, contudo, alcança seus objetivos preliminares de trazer uma reflexão sobre a problemática que norteia a pesquisa: As políticas públicas impactam na geração de renda e na transformação da realidade socioeconômica das mulheres, chefes de famílias, no município de Feira de Santana, Bahia?

As mulheres, hoje, são as principais mantenedoras das famílias e necessitam de políticas públicas específicas que contemplem questões como gênero e a função de provedora do lar. É salutar os avanços quando o assunto é desigualdade de gênero ou desrespeito aos direitos humanos e sociais das mulheres. Entretanto, tais avanços não reverteram o quadro de diferenças em vários campos, sobretudo naqueles referentes às políticas públicas.

O objetivo geral de investigar a interlocução teórico/prática das mulheres chefes de famílias, seus desafios, contribuições e potencialidades, relacionando-os com as tensões existentes entre as mulheres chefes de famílias, as políticas públicas e a sua contextualização teórico epistemológica, foi validado, considerando as discussões epistemológicas sobre a mulher, como ela era vista e tratada pela sociedade, além dos desafios enfrentados na condição de chefe familiar e a necessidade de políticas públicas que contemplem essas especificidades e a coloquem no papel de sujeito social e político. Todas essas reflexões irão contribuir para a fundamentação teórica da pesquisa em curso. 
Contudo, determinadas ideias devem ser discutidas na ciência ou na política como elementos que contribuam para o empoderamento dessas mulheres, chefes de famílias, à luz de uma compreensão mais profunda dessa realidade, e que se abram horizontes de possibilidades, de transformação das questões sociais, mediante a ação e políticas públicas de gênero eficazes.

Nesse contexto, é de fundamental importância a ação perspicaz do Estado que, por meio de políticas públicas efetivas, assume a capacidade de refletir sobre o grau de participação dos atores sociais no desenvolvimento de processos de cidadania, interação política, direitos e garantias que tenham uma abrangência eficiente perante a sociedade.

Ao elegermos a longevidade, a educação e renda indicadores socioeconômicos, utilizando o caso de Feira de Santana, na Bahia, a tese, em andamento, pretende elaborar um modelo que alcance todo o Estado, na busca da eficiência, eficácia e efetividade de políticas públicas para as mulheres geradoras de renda nos respectivos municípios.

\section{Referências}

ALMEIDA, Gracineide Silva de. Buscando Estratégias de Sobrevivência: um estudo da condição socioeconômica de famílias chefiadas por mulheres em Novos Alagados. 2005. Dissertação de Mestrado, Universidade Católica de Salvador, Salvador.

BIT'TAR, Eduardo C. B., ALMEIDA, Guilherme Assis de. Curso de Filosofia do Direito. 11. ed. São Paulo: Atlas, 2015.

CARVAlHO, Luiza M.S. Santos. A Mulher Trabalhadora na Dinâmica da Manutenção e da Chefia Domiciliar. In.: Revista Estudos Feministas. RJ: Instituto de Filosofia e Ciências Sociais - IFCS/UFRJ, vol. 6 n $1 / 1998$.

COUlANGES, Fustel de. A Cidade Antiga. Edipro. 3ª . ed. São Paulo, 2001.

DYE, Thomas D. Understanding public policy. Englewood Cliffs, N.J.: Prentice-Hall, 1984.

FERREIRA, Maria Luísa Ribeiro (org.), O que os filósofos pensam sobre as mulheres. Lisboa, Centro de Filosofia, 1998.

GUIMARÃES, José Ribeiro Soares. Participação feminina no mercado de trabalho: expansão e iniquidade. Bahia Análises e Dados, Salvador, SEI, v. 10. n.4, mar., 2001, p. 154-168.

HABERMAS, Jürgen. Para o uso pragmático, ético e moral da razão prática. In: Boletim de Estudos Avançados da USP, USP, IEA, trad. de Márcio Suzuki, set./dez. 1989, v. 3, n. 7. 
. Consciência moral e agir comunicativo. Rio de Janeiro: Tempo Brasileiro, 1989.

IPEA. Diagnóstico e desempenho recente do Pacto Nacional pelo Enfrentamento à Violência contra a Mulher. In: IPEA. Brasil em Desenvolvimento: Estado, planejamento e políticas públicas, v. 3. Brasília: Ipea, 2010.

LYNN, L. E. Designing public policy: a casebook on the role of policy analysis. Santa Monica, Calif.: Goodyear, 1980

MACEDO, Márcia dos Santos. Tecendo o fio e segurando as pontas: mulheres chefes de família em Salvador. In.: BRUSCHINI, Cristina; PINTO, Céli Regina (orgs.) Tempos e Lugares de Gênero. São Paulo: FCG: Editora 34, 2001.

MARSHALL, Thomas Humphrey. Social policy in the twentieth century. 2. ed. Londres: Hutchinson, 1967.

. Cidadania e Classe Social [Ed. atual trad. e rev. Por EaD/CEE/MCT], 2. ed. Brasília: Senado Federal, Centro de Estudos Estratégicos, Ministério da Ciência e Tecnologia, 2002.

MASTRODI, Josué; AVELAR, Ana Emília Cunha. Cadernos de Direito, Piracicaba, v. 17(33): 3-27, jul.dez. 2017 • ISSN Eletrônico: 2238-1228.

MESSEDER, S. A. E PRECISA ISSO?! : Desconstruindo o fio das masculinidades nas vivências de mulheres masculinizadas na Escola e no Mundo do Trabalho. In: Tereza Rodrigues Vieira. (Org.). Minorias Sexuais Direitos e Preconceitos. 01 ed.Brasilia: Consulex, 2012, v. 01.

NASCIMENTO. Janaína Xavier do. Políticas Públicas e desigualdade de gênero na sociedade brasileira: considerações sobre os campos do trabalho, da política e da ciência 1, Londrina: Mediações, V. 21 N. 1, P. 317-337, JUL./DEZ. 2016

NOGUEIRA, Maria da C. de Oliveira Carvalho. Os Discursos das Mulheres em Posição de Poder. Disponível em <http://pepsic.brspsi.org.br/pdf/cpst/v9n2/v9n2ao5.pdf>. Acesso em 03 dezembro de 2012.

PETERS, B. GUY. American public policy. Chatham, NJ, EUA: Chatham House, 1986.

PLATÃO. A República. Tradução: Pietro Nassetti. São Paulo: Martim Claret, 2009. 
PRIETO, Maria Helena Ureña. Breves interrogações sobre a condição feminina na obra de Platão. HVMANITAS - Vol. XLVII. 1995.

REALE, Giovanni. História da filosofia grega e romana - Aristóteles. 3. ed. São Paulo: Loyola, 2007, v.4.

SOUZA, R. G. Poder local e gestão de políticas públicas. In: E. V. Francisco \& C. C. Almeida (eds.). Trabalho, Território, Cultura: novos prismas para o debate das políticas públicas, São Paulo: Cortez, 2007.

WEBER, M. Economia e Sociedade. Brasília: UNB, 2000. 2v.

A Política como vocação. Brasília: UNB, 2003.

Recebido em: setembro de 2019.

Aprovado em: outubro de 2019. 